\section{Andrii Papa, Yevhen Shemet, Andrii Yarovyi}

\title{
ANALYSIS OF FUZZY LOGIC METHODS FOR FORECASTING CUSTOMER CHURN
}

The object of research is the process of predicting the churn of customers of telecommunications companies based on fuzzy logic and neural networks. The research carried out is based on the application of an approach that is implemented through the combined use of fuzzy logic and neural networks. The main assumption of the study is the hypothesis that the use of a fuzzy neural network formed on the basis of fuzzy logic algorithms can improve the accuracy of predicting customer churn relative to available solutions. This result can't be achieved neglecting the existing resource constraints and requirements, which must be determined separately for each case of research. The relevance of the problem of forecasting customer churn for companies with a large number of users is considered. A model for predicting customer churn is proposed based on the combined use of fuzzy logic and neural networks. The main feature of this approach is that a test sample of normalized data is used at the basis of fuzzy neural networks, which are processed to form the parameters of membership functions that correspond to the inference system, that is, conclusions are made on the basis of a fuzzy logic apparatus. Also, to find the parameters of the membership function, neural network algorithms are used. Such systems can use previously known information, learn, gain new knowledge, predict time series, perform image classification, and besides, they are quite visual to the user. The application of methods of fuzzy logic is considered, they make it possible to obtain a result in the form of a fuzzy inference. The expediency of choosing these methods is explained by the fact that they were previously used in fuzzy automatic control systems and showed sufficiently high quality results. The expediency and prospects of using the proposed approach in the problem of predicting the outflow of customers of telecommunications companies are shown, and the results of software implementation are presented.

Keywords: predicting customer churn, fuzzy logic, membership function, fuzzy neural network, Mamdani algorithm, Sugeno algorithm.

\section{Introduction}

Today one of the most urgent tasks for companies working with a large number of users is to retain existing and attract new customers. Despite the serious interest of analysts and scientists in the problem of retaining consumers of services, one source does not provide ready-made mathematical algorithms and software solutions that can fully solve this specific problem for a specific service in a specific region. Most of the economic problems have to be solved under conditions of uncertainty of the initial information [1]. Thus, to solve the problem of predicting customer churn in order to retain existing users, it is advisable to analyze the methods of fuzzy logic, with the possibility of their combined use with neural networks. So, the object of research is the process of predicting the churn of customers of telecommunications companies based on fuzzy logic and neural networks. The aim of research is to study existing methods of fuzzy logic, as well as improve the forecast of customer churn through the use of a fuzzy neural network.

\section{Methods of research}

The research is based on the application of the approaches described in $[2,3]$. The main assumption of the study is the hypothesis that the use of a fuzzy neural network formed on the basis of fuzzy logic algorithms can improve the prediction of customer churn relative to available solutions. For this task, an important aspect is to take into account the features of the initial information. Based on its reliability, the initial information can be divided into deterministic, reliable and fuzzy. The concept of fuzziness is largely due to subjectivity and rough ideas about any indicator of the system. Unlike probabilistic, fuzzy values are characterized not by a distribution law based on objective statistics, but by a membership function. It shows the degree of belonging of the considered variable from complete non-belonging (0) to complete belonging (1) to the physical nature of phenomena $[4,5]$.

Usually the least «accurate» information is clear enough, but in most cases it remains the only one that can characterize many processes in a particular industry.

Either time series or regression models can be used to predict factors. In addition, there are many other approaches to predicting customer churn. However, despite the variety of existing forecasting methods, accurate modeling is difficult due to the non-linear relationship between churn and the factors on which it depends.

Let's consider an approach built using fuzzy logic algorithms and neural networks. The main feature of this approach is that a test sample of normalized data is used at the basis of fuzzy neural networks, which are processed to formulate the parameters of membership functions that correspond to the inference system, that is, conclusions are 
made based on the apparatus of fuzzy logic. Also, to search for the parameters of membership functions, neural network algorithms are used that perform the function of their training. Such systems can use previously known information, learn, gain new knowledge, predict time series, and perform image classification. In addition, they are quite visual for the user.

For a numerical assessment of predicting customer churn, algorithms were analyzed that provide for retrospective calculations taking into account the transition parameters. The possibility of practical implementation of the presented algorithms can be limited only by the lack of initial information and the complexity of the software implementation.

Based on the study of the behavior of the test sample for a specified period (quarter), a forecast is made about the prospect of customer churn. The input parameters are given interval, that is, each of the parameters was given the minimum and maximum values (confidence interval) When developing a fuzzy neural network, the main task of which is to predict customer churn, the application of the Mamdani and Sugeno algorithms was considered, which makes it possible to obtain a result in the form of fuzzy inference.

Mamdani algorithm found application in the first fuzzy automatic control systems, which was proposed in 1975 for controlling a steam engine [6]. The algorithm is formed in the subject area in the form of fuzzy predicate rules of the form:

$$
\begin{aligned}
& \Pi \text { 1: IF } \mathrm{x} \in \mathrm{A} \text { 1, THEN } \mathrm{z} \in \mathrm{B} \text { 1, } \\
& \text { П_2: IF } x \in \text { A_2, THEN } z \in \text { B_2, } \\
& \text { П_n: IF } x \in \text { A_n, THEN } z \in \text { B_n, }
\end{aligned}
$$

where $\mathrm{x}$ - input variable (identifier for known data values); $\mathrm{z}$ - output variable (an identifier for the data value to be calculated); $\mathrm{A}_{-} \mathrm{i}$ and $\mathrm{B} \_\mathrm{i}$ - fuzzy sets defined on $\mathrm{X}$ and $\mathrm{Z}$, respectively, using the membership function and the output variable.

The algorithm is used mainly in problems of fuzzy modeling, where it can significantly reduce the amount of computation [7].

Sugeno algorithm looks like this:

Formation of the rule base of fuzzy inference systems. The rule base uses only fuzzy production rules in the form:

RULE <1>: IF $(x \in A-1$ I $y \in$ B 1$)$, THEN, z_1 $1=f\left(x \_1, \ldots, x \_n\right)$,

RULE $<2>$ : IF $\left(x \in A \_2\right.$ I $y \in$ B 2$)$, THEN, z_2 $=f\left(x \_1, \ldots, x \_n\right)$,

where $\mathrm{x}, \mathrm{y}$ - input variables; $\mathrm{A} \_\mathrm{i}, \mathrm{B} \_\mathrm{i}-$ numerical values of input parameters; $\mathrm{z} \_1=\mathrm{f}\left(\mathrm{x} \_1, \ldots, \mathrm{x} \_\mathrm{n}\right)-$ arbitrary crisp function.

The steps of the algorithm can be described as follows:

1. Fuzzifications of input variables defining statements are carried out similarly to the Mamdani algorithm [8].

2. Aggregation of the premise of the rules of fuzzy production is carried out similarly to the Mamdani algorithm using the classical fuzzy logical operation «AND» of two elementary statements:

$\mathrm{A}, \mathrm{B}: \mathrm{T}(\mathrm{A} \cap \mathrm{B})=\min \{\mathrm{T}(\mathrm{A}) ; \mathrm{T}(\mathrm{B})\}$.
3. The activation of the conclusions of the rules of fuzzy production is carried out in two stages. At the first stage, the degree of truth from the conclusions (consequent) of fuzzy production rules, which assign real numbers to the output variable, are found similarly to the Mamdani algorithm, as the algebraic product of the weight coefficient and the degree of truth of the antecedent of a given fuzzy production rule. At the second stage, in contrast to the Mamdani algorithm, for each of the production rules, instead of constructing the membership functions of conclusions in an explicit form, a clear value of the output variable $w=\varepsilon 1 a+\varepsilon 2 b$ is found. Thus, each $i$-th production rule is assigned a point $\left(c_{-} i, w_{-} i\right)$, where $c_{-} i$ degree of the production rule truth, $\left.\mathrm{w}_{-} \mathrm{i}\right)$ - clear value of the output variable defined in the consequent of the production rule.

4. The accumulation of the conclusions of the rules of fuzzy production is not carried out, since at the stage of activation, already obtained discrete sets of clear values for each of the output linguistic variables.

5. Defuzzification is carried out as in the Tsukamoto algorithm [9, 10].

\section{Research results and discussion}

On the basis of testing the networks created using these algorithms, a fuzzy neural network was selected, in which the Sugeno algorithm is implemented. The number of training cycles for the created fuzzy neural network was 1000 epochs. The created network has four inputs, two inputs for each of the input parameters (the minimum and maximum values for each input parameter, respectively). Two membership functions were chosen for each input variable. Each of these membership functions is trapezoidal.

For the output parameter, the type of the membership function was supplied as a constant. The network was trained on open source churn data from a telecommunications company. Then it was tested on a sample of data that were not used in the training sample. Fig. 1 shows a graph of the predicted values of customer churn based on the created software implementation, as well as the actual values of transitions. Fig. 2 shows the error in predicting customer churn generated by a fuzzy neural network. As a result, the behavior of the network is quite adequate, the average forecast error is $2.9 \%$.

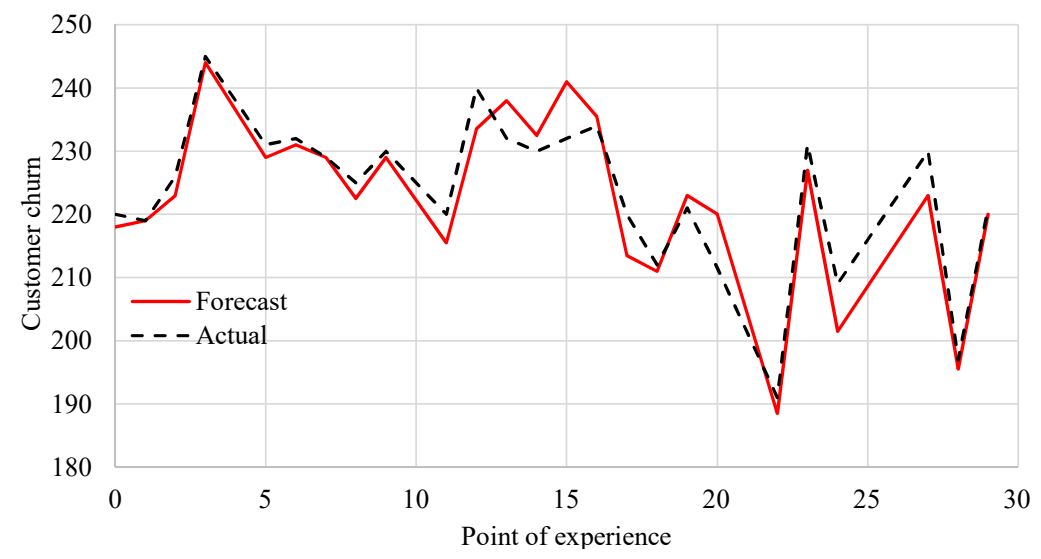

Fig. 1. Actual and forecast churn values 


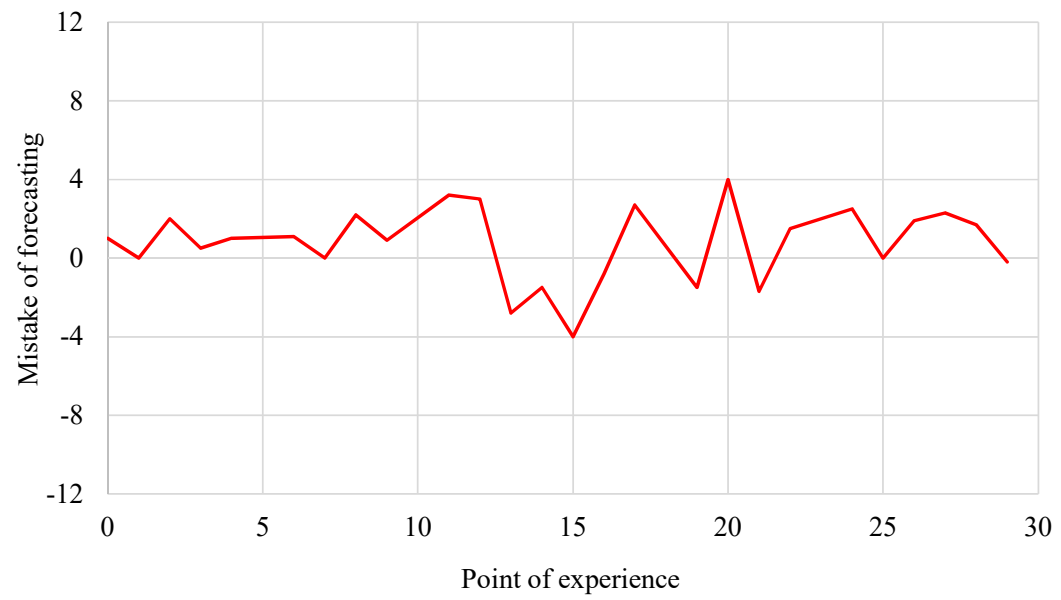

Fig. 2. Error predicting customer churn

The results of the analysis of fuzzy logic methods for predicting customer churn show the feasibility and prospects of applying the chosen approach. Therefore, when improving information technology for analyzing customer churn, it is promising to use integrated methods of fuzzy logic and neural networks using the Sugeno algorithm, which can improve the accuracy of predicting the churn of customers of a telecommunications company.

\section{Conclusions}

The combined use of fuzzy logic and neural networks in the process of predicting the churn of customers of telecommunications companies is proposed. A feature of this combined application is that a test sample of normalized data is used at the heart of fuzzy neural networks, which are processed to form the parameters of the membership function that best correspond to the inference system. Also, to search for the parameters of the membership function, neural network algorithms are used that perform the function of their training. A model for predicting the churn of customers of a telecommunications company is investigated, which differs from the known ones by the use of the Sugeno algorithm in the development of a fuzzy neural network, which provided a $5.1 \%$ increase in the accuracy of predicting the churn of customers of a telecommunications company.

The research results show the feasibility and prospects of applying the selected approach in terms of improving information technology for predicting the churn of customers of a telecommunications company. The results are planned to be used in further research in order to improve the accuracy and speed of forecasting customer churn.

\section{References}

1. Srinivasan, D., Tan, S. S., Chang, C. S., Chan, E. K. (1998). Practical implementation of a hybrid fuzzy neural network for one-day-ahead load forecasting. IEE Proceedings Generation, Transmission and Distribution, 145 (6), 687. doi: http://doi.org/10.1049/ ip-gtd:19982363

2. Papa, A. A., Yarovyi, A. A., Prozor, O. P. (2019). Informatsiina tekhnolohiia analizu vidtoku kliientiv telekom-kompanii. XLVIII Naukovo-tekhnichna konferentsiia fakultetu informatsiinykh tekhnolohii ta kompiuternoi inzhenerii. Available at: https://conferences.vntu.edu.ua/index.php/all-fitki/all-fitki-2019/ paper/view/7324

3. Kulyk, O. O., Yarovyi, A. A. (2016). Klasyfikatsiia pliamopodibnykh zobrazhen $\mathrm{z}$ riznym stupenem spotvorennia na bazi nechitkykh system $\mathrm{z}$ bahatopotokovoiu obrobkoiu. MIT-2016. Odessa: VMV, 145-146.

4. Zadeh, L. A. (1965). Fuzzy sets. Information and Control, 8 (3), 338-353. doi: http://doi.org/10.1016/s0019-9958(65)90241-x

5. Zadeh, L. A. (1968). Fuzzy algorithms. Information and Control, 12 (2), 94-102. doi: http://doi.org/10.1016/s00199958(68)90211-8

6. Mamdani, E. H. (1974). Application of fuzzy algorithms for control of simple dynamic plant. Proceedings of the Institution of Electrical Engineers, 121 (12), 1585. doi: http://doi. org/10.1049/piee.1974.0328

7. Mamdani, E. H., Assilian, S. (1975). An experiment in linguistic synthesis with a fuzzy logic controller. International Journal of Man-Machine Studies, 7 (1), 1-13. doi: http://doi. org/10.1016/s0020-7373(75)80002-2

8. Diakonov, V., Kruglov, V. (2001). Algoritmy nechetkogo vyvoda: algoritm Mamdani i algoritm Sugeno. Matematicheskie pakety rasshireniia MATLAB. Saint Petersburg: Piter, 307-309.

9. Jager, R. (1995). Fuzzy logic in control. Delft: Techniscke Universitet, 313.

10. Sugeno, M. (1977). Fuzzy measures and fuzzy integrals: a survey. Fuzzy automata and decision processes. North-Holland, 89-102.

Andrii Papa, Postgraduate Student, Department of Computer Science, Vinnytsia National Technical University, Vinnytsia, Ukraine, e-mail: papa.andriy@gmail.com, ORCID: http://orcid.org/00000002-7753-8576

Yevhen Shemet, Postgraduate Student, Department of Computer Science, Vinnytsia National Technical University, Vinnytsia, Ukraine, e-mail: yevhene@gmail.com, ORCID: http://orcid.org/ 0000-0001-5067-1900

Andrii Yarovyi, Doctor of Technical Sciences, Professor, Head of Department of Computer Science, Vinnytsia National Technical University, Vinnytsia, Ukraine, e-mail: a.yarovyy@vntu.edu.ua, ORCID: http://orcid.org/0000-0002-6668-2425 